\title{
Towards a Monitoring-Aware Design Process for CSCL Scripts
}

\author{
María Jesús Rodríguez-Triana, Alejandra Martínez-Monés, Juan Ignacio \\ Asensio-Pérez, and Yannis Dimitriadis \\ GSIC-EMIC, University of Valladolid, Spain \\ \{chusegsic, amartine@infor, juaase@tel, yannis@tel\}.uva.es \\ http://www.gsic.uva.es
}

\begin{abstract}
Scripting and monitoring are two well-known strategies to enhance collaboration in CSCL settings. Teachers are incorporating them increasingly into their practice, however it is not common to find both of them aligned. We are working on the definition of a learning design process that takes monitoring issues into account and leads to better and more efficient monitoring when the scripts are put into practice. Moreover, if the learning design is based on patterns, the information given by these patterns can help to shape this enhanced design process. This paper presents a pilot study where a participatory design approach was followed. The first author and a teacher co-designed a CSCL situation in higher education based on the Jigsaw pattern. The analysis of the co-design process gave us a first structure of the data to be considered in monitoring-aware learning designs and a set of measures for enhancing monitoring at design-time.
\end{abstract}

Keywords: CSCL, learning design, scripting, monitoring, collaborative learning flow patterns

\section{Introduction}

Scripting and monitoring are two strategies to shape group interactions in ComputerSupported Collaborative Learning (CSCL) scenarios [1] [2]. Scripting focuses on structuring the learning scenario, providing students with a set of instructions that guide potentially fruitful collaboration. It is performed at design-time, before the learning situation starts. Monitoring plays a relevant role in the regulation providing awareness information during the enactment of the learning situation [3].

It has been argued that monitoring could be more efficient if its requirements are considered at design-time [4] [5], as well as it has been done with the evaluation or the assessment [6]. In this direction, we are working on the definition of a monitoring-aware design process, where the specific characteristics of the learning design (constraints [7] [8]) guide the configuration of the monitoring process and where the requirements posed by monitoring are considered at design-time. Our work aims at exploiting the mutual relationships between monitoring and design, in order to improve both.

It is known that modeling potentially effective CSCL scripts is a difficult task (especially for non-expert designers), and also has been proven that the use of patterns 
that reflect good practices in structuring collaborative learning is helpful [9]. A particular type of CSCL scripting patterns are the Collaborative Learning Flow Patterns (CLFPs), which capture the essence of well-accepted techniques for structuring the flow of collaborative learning activities [10].

In a previous work [11], we explored whether the use of CLFPs could be useful to guide monitoring. We found initial evidence that being aware of the pattern used in a script increases the opportunities of detecting critical situations when the script is put into practice. This way, monitoring process is more efficient, since the critical points are identified in advance, and monitoring can focus on detecting them, instead of on modeling the whole collaborative process.

However, the information provided by the CLFP is not sufficient. Other data derived from the specific characteristics of the learning situation is also needed to inform monitoring. In order to move forward in the definition of the aforementioned monitoringaware design process, we set up a new pilot study, reported in this paper, with the intention of identifying the elements that should be considered in this process. The complexity of the envisioned process, and the mutual dependencies between design and monitoring call for a co-design process [12] [13]. We adopted this approach, with the teacher taking the role of expert "learning designer" and the researcher the role of "monitoring" expert. The requirements of both were considered and combined, in order to produce a "monitorable script" [11]. The goal was twofold: to identify the elements that would become part of a monitoring model on which to base the process, and to gather evidence on the usefulness of the proposed process from the teacher's point of view.

The work reported in this paper is aimed at answering the research question about which are the aspects that should be considered at design-time in order to monitor the learning scenario. This paper describes how the co-design process helped to identify these aspects. The paper also includes the main reflections from the participant teacher, who evaluated positively the monitoring process that was followed during the study.

The remaining of this paper is structured as follows: Section 2 describes the overall approach and previous work done by the authors towards this end. Section 3 presents the pilot study, and finally, conclusions and future work are summarized in Sect. 4.

\section{General Approach}

As mentioned beforehand, previous research has pointed out that synergies may appear when monitoring and design are aligned. On the one hand the design would benefit from taking into account the especial requirements posed by monitoring, and on the other hand, the integration in the design of the monitoring issues could help to obtain results better tailored to the teacher's needs.

However, no integration of monitoring has been observed into mainstream CSCL practices. Martínez et al. [4] classify the integration problems into two types: those caused by technological reasons and those that depend on the decisions taken during the design of the learning scenario.

Regarding the technological challenges, the main issues are related to the data gathering, interpretation, and integration. These obstacles increase when the technological 
context is heterogeneous and decentralized [14]. In these settings, it is necessary to process and take into account the information of distinct data sources in order to obtain a general and realistic view of the learning activities. In [15] we delved into the problem of data gathering in technologically decentralized learning environments for monitoring purposes. A solution was proposed to add monitoring functionalities to an existing architecture devoted to integrate virtual and personal learning environments (VLEs and PLEs) with external tools, named GLUE! (Group Learning Uniform Environment) [16]. Initial evidence was obtained on the capabilities of the proposed architecture to gather relevant information about the users' actions during the learning process.

In order to guide the configuration of the monitoring process, it is necessary to identify the constraints [7] [8] of the learning design that must be accomplished during its implementation. To address this issue, we analyzed the constraints of pattern-based CSCL scripts, in particular those based on CLFPs. From this analysis, we proposed a method to get an automated and higher level view about the evolution of the learning process by combining monitoring and pattern-based scripting. These ideas were tried out in an authentic learning scenario, and we found evidences that support that being aware of the pattern used in a script increases the opportunities of automatically detecting critical situations while the script is put into practice [11]. However, in this proposal the teacher was not involved in the configuration of the monitoring.

In summary, in our previous work we have tackled with the problems of the integration of tools and data at a technological level, and of how the CLFP constraints can help to shape a more efficient monitoring process. However, in order to achieve our goal of defining an enriched learning design process considering the requirements posed by monitoring, we still needed to gain insight on the factors that influence this process. We needed to identify the elements of a monitoring model that would become the base for the systematization of the monitoring-aware learning design process. This is the main goal of the study reported in this paper.

\section{Identifying the Elements that Guide Monitoring: An Exploratory Study}

This section reports the study that was set up in order to gain insight into the elements on which to sustain the envisioned monitoring-aware learning design process previously discussed. In this process, teacher and researcher followed a co-design approach of the learning and monitoring processes, thus ensuring that the needs of both were taken into account. Later on, the resulting monitoring-aware script was put into practice using the aforementioned GLUE! architecture. The participants' actions were monitored in order to test whether the overall design was being accomplished as expected.

This section is structured as follows: first, we present briefly the main characteristics of the case; then, we explain how the monitoring issues were taken into account during the co-design process, as well as their impact on the enactment; and finally, the section ends with the discussion of the results obtained from the case study. 


\subsection{Context and Methodologies of the Study}

The case study presented in this section was developed from February 17th to March 9th, 2012, and took place within a course on "Learning methods" of a Preservice Master's Degree in Secondary Education, at the University of Valladolid (Spain), with 14 students attending the course. During this course, students had to analyze different teaching and learning methods. In order to help them in the understanding and internalization of these topics, they were asked to elaborate a poster with their choices about the most suitable learning methods for a concrete learning context. To elaborate this poster, students worked in a blended CSCL setting, interleaving face-to-face with distance activities mediated by ICT (Information and Communication Technology) tools.

The collaboration script implemented a Jigsaw CLFP. According to the definition of jigsaw given by [17], this pattern is especially intended for contexts in which several small groups are facing the resolution of the same problem, and typically, the problem to be solved is complex and can be easily divided into sections or independent sub-problems. For such context, this pattern provides some guidelines (a collaborative learning flow and a schema for group structuring) devoted to promote the feeling that team members need each other to succeed (positive interdependence), to foster discussion in order to construct student's knowledge, and to ensure that students must contribute their fare share (individual accountability).

The jigsaw suggests a sequence of activities consisting of: an individual phase in which each participant works individually on a particular sub-problem; an expert phase where participants studying the same problem meet in an expert group for exchanging ideas, becoming experts in the section of the problem given to them; and finally a jigsaw phase where experts from each expert group meet in jigsaw groups to contribute with their expertise to solve the whole problem. The requirements that must be satisfied to accomplish this pattern are summarized in Table 1. These requirements are taken from the CLFPs analysis described in the previous Section, where CLFPs where studied in order to identify the critical points that could guide the monitoring process [11].

With this case study we aimed at illuminating three issues that would help us to gain insight into our research goal. These issues were: "in which ways the consciousness about the CLFP constraints modifies the learning design?", "which are the parameters that model the monitoring configuration?" and, in a CSCL scenario characterized by the integration of ICT tools and the combination of face-to-face and distance activities, "which are the required conditions for collecting relevant information?".

In order to answer these questions, we found a co-design process between teacher and researcher the most suitable way to obtain a monitorable CSCL script and, at the same time, identify and analyze the relevant decisions made during its development. Then, the script was put into practice, and the results obtained were compared to those expected. These results were triangulated with data coming from observations carried out by the teacher during the face-to-face sessions; two questionnaires handed to the students about their work in groups; and several interviews to the teacher during and after the learning situation. This triangulation allowed us to verify the validity of the monitoring results and helped us collect the feedback of the teacher. 


\subsection{The Co-Design Process}

As aforementioned, during this phase teacher and researcher worked together on a design that took into account both the pedagogical and monitoring needs. Throughout this process, we pursued to identify different dimensions and attributes of the learning design that may guide a design-based monitoring process.

The co-design process consisted of two cycles. First, the teacher designed the learning situation following the guidelines given by the pattern-design process. The researcher contributed with her knowledge on the pattern, observing how the decisions taken by the teacher influenced monitoring, and intervening where necessary to ensure a better process. In the second cycle, both teacher and researcher worked together, exploring additional ways on which the script could be improved in order to obtain the information needed to detect the critical situations given by the pattern. A summary of the main decisions made both parts of the co-design process have being summarized in Table 2. Italicized text is used for the decisions made in the second cycle of the study in order to improve the monitoring process.

First Cycle: The Pattern-Driven Co-Design. Focusing on the learning objectives, the teacher designed the scenario following a pattern-based learning design process. This process was supported by the authoring tool Web Instance Collage [18], which defines four main steps: (1) the definition of objectives and prerequisites of the learning design, (2) the creation of groups and the corresponding allocation of students, (3) the particularization of the activity learning flow and (4) the provision of resources (contents and tools). Here, we will focus on the last three ones (group creation, definition of the activity learning flow and provision of resources) as current aspects of interest from the standpoint of monitoring. A summary of the main decisions taken during these codesign cycles is presented in Table 2.

Throughout this process, focusing on the monitoring issues, the researcher informed the teacher about constraints that should be accomplished according to the pattern and the impact that they could have on the learning situation if they were not met. Table 1 summarizes the analysis of the jigsaw constraints.

The first of these steps, group creation, is of paramount importance for the success of the learning situation. The information obtained from the group structuring is very useful for the monitoring labor, because it gives information about the expected structures of interactions in a given activity. In our case, the design was based on a jigsaw CLFP, group formation consisted on distributing students in concrete jigsaw and expert groups. As mentioned in Table 1, each expert group had to contain at least one member of each jigsaw group, and viceversa, each jisgsaw group had to include at least one member of each expert group. Expert groups have to include as many members as the number of sub-problems identified. At design-time, the designer can be advised to replicate these "roles" of expert and/or member of a jisgsaw group, in the cases where the absence of one or several students is known in advance. This happened in the case being described. After a query to the students, the teacher decided to replicate one of the experts in a jigsaw group, because one of the students was not expected to assist to the course, in spite of being enrolled in it. From the 14 students, 3 jigsaw groups and 4 
Table 1. List of constraints of the jigsaw CLFP. $\mathbf{X}$ represents that the restriction must be satisfied in that specific phase of the pattern (individual, expert and jigsaw).

\begin{tabular}{ccccc}
\hline $\begin{array}{c}\text { Structuring } \\
\text { constraints }\end{array}$ & $\begin{array}{c}\text { Individual } \\
\text { (individual) }\end{array}$ & $\begin{array}{c}\text { Expert } \\
\text { (collaborative) }\end{array}$ & $\begin{array}{c}\text { Jigsaw } \\
\text { (collaborative) }\end{array}$ & \multicolumn{1}{c}{ Description } \\
\hline group sizes & $\mathbf{X}$ & $\mathbf{X}$ & $\begin{array}{l}\text { There must be enough partici- } \\
\text { pants to collaborate. }\end{array}$ \\
\hline expert group sizes & $\mathbf{X}$ & $\mathbf{X}$ & $\begin{array}{l}\text { The group sizes must be large } \\
\text { enough to provide participants to } \\
\text { each jigsaw group. }\end{array}$ \\
\hline jigsaw group sizes & $\mathbf{X}$ & $\begin{array}{l}\text { The group sizes must be large } \\
\text { enough to gather experts from all } \\
\text { areas. }\end{array}$ \\
\hline no. of subproblems & $\mathbf{X}$ & $\begin{array}{l}\text { There must be at least 2 subprob- } \\
\text { lems but no more than the half of } \\
\text { the class to allow for collabora- } \\
\text { tion. }\end{array}$ \\
\hline no. of expert groups & $\mathbf{X}$ & $\mathbf{X}$ & $\begin{array}{l}\text { There must be at least one group } \\
\text { of experts for each subproblem } \\
\text { but no more than the half of the } \\
\text { class to allow for collaboration. }\end{array}$ \\
\hline group dependences & & $\mathbf{X}$ & $\begin{array}{l}\text { The number of jigsaw groups } \\
\text { must be in accordance to the } \\
\text { number of experts of each area. }\end{array}$ \\
\hline
\end{tabular}

expert groups were defined. 12 students were assigned to these groups in order to ensure the pattern constraints, and the other two were allocated to existing groups. These aspects are not normally possible to foresee, but will only appear when the activity is put into practice. As we will describe later in this section, the monitoring process is then the responsible of testing these critical points defined by the CLFP. This would, for example, help to detect whether a particular jigsaw group is lacking the contribution of one expert to it.

The next design step was the description of each activity within the learning flow described by the CLFP. This was done by the teacher, who defined the concrete tasks that the students had to accomplish during the three phases of the jigsaw pattern. At the individual phase, each participant had to studied two learning methods out of an overall number of six. At the end of the phase they had to write an individual summary about the studied methods. During the expert phase, those students that had been working on the same methods joined into a expert group and designed collaboratively a concept 
map with the main ideas of each of the two methods they had studied. Once the expert phase finished, students were distributed in jigsaw groups. During the jigsaw phase, the students worked in their jigsaw groups, and the planned activities consisted on the elaboration of a poster where they had to choose two methods out of the six they had studied in the group, and justify their choice, discussing their suitability for the learning contexts they were working on. The poster and its presentation was evaluated by the rest of the classmates in an oral presentation at the end of the activity. The definition of the activities was complemented with decisions about their duration (with explicit starting and ending points), their interactivity type (face-to-face, through computers or blended, and their physical locations (inside and/or outside the classroom). From the monitoring point of view, being aware of which activities are to be carried out individually or in groups, (and in which groups), gives information about which evidences should be gathered in each phase. Besides this, the time limits are needed to narrow the period of the analysis; and the combination between the interactivity type and the location gives information about which evidences are applicable and potentially useful (i.e., presence in a face-to-face activity in groups, or submission of a deliverable in an individual task, etc.) or not (i.e., it is not appropriate to monitor the number of individual accesses to a tool if only a (unique) group submission is expected at the end of the task). Besides this, some situations, such as face-to-face interaction in the classroom, need additional sources of data not provided by the tools, in order to register the presence or absence of students in that task.

Last step in the design process is the provision of necessary resources. Apart from the bibliography, the design required ICT tools for collaborative drawing and writing as well as on-line questionnaires. Then, the next step involved the searching of tools that satisfied the teacher's needs and at the same time allowed us to harvest data about the users' actions. On the one hand, the teacher posed the restriction of using Medi$a W i k i{ }^{1}$ to centralize the access to all the resources and activities and, on the other hand, the researcher was interested on tools that provide data about the users' actions. Both of them agreed on using the GLUE! architecture [16] because it allows the integration of external tools on MediaWiki and besides, it facilitates the collection of information from the different technologies used in the learning scenario [15]. Initially, the teacher proposed to use Text 2 Mind $\mathrm{Map}^{2}$, a web application for development of conceptual maps, and Google Forms ${ }^{3}$ for the on-line questionnaires. However, since Text 2 Mind Map did not offer any information about user actions, it was substituted by Dabbleboard $^{4}$ by proposal of the researcher. From such technological context it was possible to detect who accessed in a specific moment to Dabbleboard or Google Forms, as well as the editions and uploads done by the users of MediaWiki. Being aware of the tools required for each activity allowed us to focus the monitoring data harvesting on the significant sources.

\footnotetext{
1 http://www.mediawiki.org

2 http://www.text2mindmap.com/

3 http://www.google.com/google-d-s/forms/

4 http: //www.dabbleboard.com/
} 
Table 2. Description of the activities included in the script. Italicized text is used for the elements that were added in the second cycle of the study in order to improve the monitoring process. (ITC - Inside the classroom / OTC - Outside the classroom)

\begin{tabular}{|c|c|c|c|c|c|c|}
\hline Phase & Activity & $\begin{array}{c}\text { Social } \\
\text { level }\end{array}$ & $\begin{array}{l}\text { Interactivity } \\
\text { type }\end{array}$ & $\begin{array}{l}\text { Physical } \\
\text { location }\end{array}$ & $\begin{array}{l}\text { Resources and tools } \\
\text { for learners }\end{array}$ & $\begin{array}{l}\text { Resources and tools } \\
\text { for teachers }\end{array}$ \\
\hline Individual & $\begin{array}{l}\text { Individual } \\
\text { study }\end{array}$ & Individual & $\begin{array}{l}\text { Through } \\
\text { computers }\end{array}$ & OTC & $\begin{array}{l}\text { - Documentation on learning } \\
\text { methods }\end{array}$ & \\
\hline \multirow{3}{*}{ Expert } & $\begin{array}{l}\text { Individual } \\
\text { summaries }\end{array}$ & Individual & $\begin{array}{l}\text { Through } \\
\text { computers }\end{array}$ & OTC & - A wiki page & $\begin{array}{l}\text { - Monitoring report } \\
\text { - Register of submissions }\end{array}$ \\
\hline & $\begin{array}{c}\text { Expert } \\
\text { consensus }\end{array}$ & $\begin{array}{l}\text { Expert } \\
\text { groups }\end{array}$ & Blended & $\begin{array}{l}\text { ITC \& } \\
\text { OTC }\end{array}$ & $\begin{array}{l}\text { - A shared board (Dabbleboard) } \\
\text { - A wiki page }\end{array}$ & $\begin{array}{l}\text { - Register of attendance } \\
\text { - Monitoring report } \\
\text { - Register of submissions }\end{array}$ \\
\hline & $\begin{array}{l}\text { Workgroup } \\
\text { report }\end{array}$ & $\begin{array}{l}\text { Expert } \\
\text { groups }\end{array}$ & $\begin{array}{l}\text { Through } \\
\text { computers }\end{array}$ & OTC & $\begin{array}{l}\text { - A questionnaire (Google } \\
\text { Forms) }\end{array}$ & $\begin{array}{l}\text { - Monitoring report } \\
\text { - Register of submissions }\end{array}$ \\
\hline \multirow{6}{*}{ Jigsaw } & $\begin{array}{l}\text { Selection } \\
\text { of methods }\end{array}$ & $\begin{array}{l}\text { Jigsaw } \\
\text { groups }\end{array}$ & $\begin{array}{l}\text { Through } \\
\text { computers }\end{array}$ & OTC & - A questionnaire (Google Forms) & $\begin{array}{l}\text { - Monitoring report } \\
\text { - Register of submissions }\end{array}$ \\
\hline & $\begin{array}{c}\text { Poster } \\
\text { development }\end{array}$ & $\begin{array}{l}\text { Jigsaw } \\
\text { groups }\end{array}$ & Blended & OTC & - A wiki page & $\begin{array}{l}\text { - Monitoring report } \\
\text { - Register of submissions }\end{array}$ \\
\hline & Peer review & Individual & $\begin{array}{l}\text { Through } \\
\text { computers }\end{array}$ & OTC & - Wiki pages & $\begin{array}{l}\text { - Monitoring report } \\
\text { - Register of participation } \\
\text { - Register of submissions }\end{array}$ \\
\hline & $\begin{array}{c}\text { Posters } \\
\text { presentation }\end{array}$ & $\begin{array}{l}\text { Jigsaw } \\
\text { groups }\end{array}$ & Face-to-face & ITC & & $\begin{array}{l}\text { - Register of attendance } \\
\text { - Register of participation } \\
\text { - Register of submissions }\end{array}$ \\
\hline & $\begin{array}{l}\text { Workgroup } \\
\text { report }\end{array}$ & $\begin{array}{l}\text { Jigsaw } \\
\text { groups }\end{array}$ & $\begin{array}{l}\text { Through } \\
\text { computers }\end{array}$ & OTC & $\begin{array}{l}\text { - A questionnaire (Google } \\
\text { Forms) }\end{array}$ & $\begin{array}{l}\text { - Monitoring report } \\
\text { - Register of submissions }\end{array}$ \\
\hline & $\begin{array}{c}\text { Peer } \\
\text { evaluation }\end{array}$ & Individual & Blended & $\begin{array}{l}\text { ITC \& } \\
\text { OTC }\end{array}$ & - A questionnaire (Google Forms) & $\begin{array}{l}\text { - Monitoring report } \\
\text { - Register of submissions }\end{array}$ \\
\hline
\end{tabular}

Second Cycle: Enriching the Design to Enhance Monitoring. Up to this point, the co-design process had been driven by the CLFP-based design approach. The teacher had followed the phases described in it, including some aspects that could improve monitoring, based on the knowledge that the researcher had on this topic. This approach had provided the teacher with a partial view about potential critical situations detected during the enactment. However, there was a need of going one step further, looking for new ways on which the design itself could be modified in order to better inform the monitoring process.

At this point the focus was on how the design could be modified in order to augment the information given by ICT tools, and help teachers detect the potential critical situations. On the one hand, we worked on enhancing monitoring data sources that could provide relevant information about the learning situation. Table 3 summarizes the informants that were identified (the technological support, the teacher herself and the 
students) depending on the physical location and interactivity type of the specific activity. As it can be observed, the interactivity type and physical location have an influence on which data sources can be used to get information about one activity. For example, activities being performed face-to-face outside the classroom can only be informed by the students themselves, while those mediated by computers inside the classroom can be informed by the data collected by the tools (ICT), by the teachers in their observations of the class and by the students themselves. Between these two extremes, other combinations of data sources exist, as shown in Table 3. It is important to note than in blended settings, there are many interactions that happen out of the scope of the technology and even of the classroom. Therefore, if these activities are to be monitored, additional monitorable data sources that capture these data are needed. We have called them data gathering activities, as their main function is to enable the collection of new data that will help to identify potential critical situations.

Table 3. Data sources needed for the monitoring of a collaborative activity depending on the interactivity type (face-to-face, computer mediated or blended) and the physical location (ITC Inside the classroom and/or OTC - Outside the classroom).

\begin{tabular}{cccc}
\hline & Face-to-face & Blended & Computer mediated \\
\hline ITC & students \& teachers & students \& teachers \& technologies & students \& teachers \& technologies \\
ITC \& OTC & students \& teachers & students \& teachers \& technologies & students \& teachers \& technologies \\
OTC & students & students \& technologies & students \& technologies \\
\hline
\end{tabular}

According to this, the learning design obtained in the previous cycle of the process was enriched with additional data gathering activities, in order to collect data from teachers and students (see text in italics in Table 2). For every activity fully or partially located in the classroom, the teacher programmed to control the attendance and participation in order to take into account what happened during the these sessions. And for those collaborative activities that happened out of the classroom, students were asked to fill out a a form about the distribution of tasks in their groups (named "workgroup reports" in Table 2).

In order to complement all these activities, and to make explicit the monitoring process, the design was enriched with additional monitoring support activities to be performed by the teacher. These activities are a means to remind teachers what they have to do to support the students during each phase of the activity (e.g. verify that all jigsaw groups submit their posters, check that every group receives feedback from at least one reviewer, control that in every group there are enough people participating, etc.). These supporting activities were informed by the workgroup reports and the monitoring reports, which collected the data gathered from the different tools integrated in the resulting learning platform, and from the attendance control forms filled out by the teacher during the activities that required this data.

Summary: Elements of Monitoring Identified in the Study. As a synthesis to this co-design process, we will summarize here the connections that emerged between learn- 
ing design and monitoring. On the one hand, the monitoring needs of data gathering caused changes in the original learning design such as choosing tools that provided data about the users' interactions, identifying complementary monitoring data sources to avoid blind spots, and including additional data gathering activities for teacher and students to collect evidence about the learning process, and monitoring support activities to be performed by the teacher.

As a result of this process, we have identified three dimensions that influence the design of the monitoring process (see Table 4). In a pattern-based process, the first one is the design pattern, by means of the constraints that must be verified during the enactment to accomplish the pedagogical objectives. These constraints, namely the collaborative learning flow and the group formation policies, constitute one of the aspects that have to be informed by the monitoring. A second dimension is related to the specific features of each activity: the time period in which an activity is of interest to study, the concrete resources that will be analyzed, how students are expected to develop the activity at a social level (individually or in groups), the interactivity type (face-to-face through computers or blended) and the location (inside and/or outside classroom). The third dimension configuring the monitoring process are teachers, who can tune the configuration of the monitoring according to their needs, specifying aspects such as when the monitoring report is to be received, the resources that have to be analyzed in each activity, which student actions are meaningful to better understand the learning process, and some additional constraints to be checked to ensure the viability of the learning situation, such as the dependences among activities not reflected in the pattern (i.e. availability of artifacts for a peer review activity).

Table 4. Compilation of parameters set by the pattern, the definition of each activity and the teacher's interests in the reported study

\begin{tabular}{ccc}
\hline Pattern & Activity & Teacher's interests \\
\hline Activity flow & Deadlines & Monitoring periods \\
Collaboration & Resources (tools, contents) & Relevant resources \\
Group formation policies & Social level & Actions to be monitored \\
& Interactivity type & Additional constraints \\
& Location & \\
\hline
\end{tabular}

\subsection{Enactment of the Learning Situation}

The script was put into practice in the context previously described. A monitoring report was sent to the teacher 15 minutes after the deadline of each activity. In most cases this report helped her to confirm that the students were following properly the script. Nevertheless, some unexpected events appeared during the enactment that helped the teacher to take regulatory measures. We describe them here, in order to illustrate the impact that monitoring had in improving the overall learning situation. 
For instance, in three of the activities: individual summaries, peer review and peer evaluation (see table 2) there was no evidence of some of the students having performed their tasks. In these situations the teacher started by verifying the work done by the students, and in the cases where the problem was confirmed, she sent a reminder, extending the deadlines. These problems could not have been detected by the teacher without the monitoring report. A similar problem arose with the workgroup report carried out by expert groups, where no evidence of participation was registered by two of the groups. However, in this case the reason was due to a technological problem with the on-line questionnaires supporting the activity, that could be easily fixed on the fly, and the students could submit their answers on time.

Another issue happened during the expert consensus. In this case, the monitoring report informed the teacher that two of the groups had not submitted their deliverable on time. If confirmed, this problem would have become a critical situation in the enactment of the pattern, as the lack of these deliverables affected the upcoming jigsaw phase. However, reviewing the work done by the students, the teacher realized that the contributions had been submitted at erroneous pages of MediaWiki.

In this latter case, as well as in the previous one, although the problem detected was not due to a fault in the students' performance, monitoring helped the teacher to detect and solve them. Overall, in this case monitoring helped the teacher to confirm with almost no effort on her part that the students were performing as expected. In the cases where this did not happen, to detect the problem and solve it before it became a real breakdown in the activity.

\subsection{Discussion}

As mentioned in the Introduction, the main goals of this study were two: to identify the elements that would become part of a monitoring model on which to base the process, and to gather evidence on the usefulness of the proposed process from the teacher's point of view. For achieving these goals we proposed three research issues, which were presented in Sect. 3.1. We discuss the results according to them.

The first issue considers the impact that the awareness of the CLFP constraints had over the learning design. The teacher participating in this study was familiar with CSCL pattern-based activities, and used CLFP-based authoring tools (Web Instance Collage in this case). The co-design process showed that, in spite of these facts, she had not had in mind any of the parameters to be controlled in the script, neither was she conscious about the impact that violations of the pattern constraints might have had over the whole design. Once the teacher realized about the potential critical points of her design and the lack of data to inform them, she decided to include new activities for students and teacher in order to facilitate the data gathering from additional sources. Besides this, her awareness on the information provided by the ICT tools increased, and she became more conscious about the need of monitoring the learning situation during their enactment.

The second issue is referred to the identification of parameters that model monitoring. This pilot study has helped us to identify three dimensions that influence the configuration of the monitoring process: the design pattern, the features of each activity and the teachers. Each one of these dimensions poses a set of parameters that condition 
what, how and when each activity should be monitored (see Table 4). This information will help us to systematize the process and move forward on the definition of a monitoring-aware learning design process.

The third and last issue is related to the conditions required for collecting relevant information in a CSCL scenario characterized by the integration of ICT tools and the combination of face-to-face and distance activities. As reflected in Table 3, depending on the interactivity type and the physical location, data sources available may vary (students, teacher and technological support). Thus, the monitoring process can not be exclusively based on the information obtained from the technological support. In those activities developed inside of the classroom, the input from teachers and/or observers is crucial to complete the information given by the ICT tools (e.g. using attendance and participations registers), as well as the feedback given by students about their work out of it. Obviously, in order to facilitate these tasks, it will be necessary to provide teachers and students with tools that support the data collection (e.g. by means of on-line forms to report the students attendance or on-line questionnaires to collect the participants comments). The study reported in this paper has shown the feasibility of this approach.

Finally, we collected some impressions and feedback from the teacher's interviews carried out during and after the experience. Reflecting on the design process, the teacher perceived the integration of monitoring issues as another aspect of the design to be taken into account that helped her to enrich the script. Besides, the teacher got a perception of better control of the learning situation since she knew where to focus the attention during the enactment. In relation to the monitoring results, they helped the teacher to detect potentially critical situations, facilitating the regulation of eventualities. Moreover, she declared that the monitoring reports were much more accurate to the teacher needs (because of her involvement in the monitoring configuration) and closer to the real facts (due to the integration of several data sources). Finally, evaluating the whole process, the teacher confirmed that improvements and results outweighed the effort devoted for the configuration of the monitoring process and the data gathering.

\section{Conclusions and Future Work}

This paper presents a case study, carried out in a higher education learning scenario with the aim of identifying the elements that should be considered in a monitoringaware learning design process. On account of the complexity of this process, and the mutual dependencies between design and monitoring, teacher and researcher worked together in a co-design process.

As a result of this process, we have identified three dimensions that influence the configuration of the monitoring process in pattern-based approaches: the design pattern, the specific features of each activity, and the teacher's choices about specific issues. From each one of them, a set of parameters that guide the monitoring process has been identified. This information will help us to systematize the monitoring-aware design process in the near future. Nevertheless, since just one researcher and teacher were involved in the co-design process, this study will be extended with other participants to avoid bias. 
The study has also provided additional information about the design process itself. By means of reflecting on the pattern constraints during the design, the teacher has included additional data gathering activities in order to inform the critical points of the script, improving both the learning design and the monitoring. These positive results support our idea of working towards the definition of a process that include monitoring as another design dimension. The process could eventually provide design-time scaffolding for helping teachers to consider monitoring implications of their pedagogical decisions.

The monitoring results provided during the enactment have demonstrated once more to be helpful for facilitating the regulation tasks, as stated by [3]. The works reported in [19] [20] and [21], analyzing the scripts flexibility and adaptability, could benefit from our proposal. Once teachers know which constraints are not being satisfied in real time, it seems to be easier for them to address the issues hampering the learning situation. This benefit is even more remarkable in heterogeneous scenarios where several ICT tools are involved [14].

Future work lines include two main threads. On the one hand, the elements that influence monitoring identified in this study must be consolidated into a model; this model will be the base for the integration of monitoring issues into existing (or new) authoring tools, in order to generate monitorable scripts. This integration will entail providing teachers with information about the "monitoring" properties of the learning tools (what information is offered about the users interactions and how can it be retrieved), in order to facilitate an appropriate selection that satisfies both the pedagogical and monitoring needs. On the other hand, we have detected a clear need of providing teachers with tools that facilitate the data gathering about the learning context (for instance attendance or participation registers), offer visualization of the monitoring results, and allow the modification of the monitoring results with the teacher's knowledge about what is happening during the enactment (e.g. confirming submissions, modifying deadlines, etc.). This is a work line very close to the approaches followed in workflow systems [22].

\section{Acknowledgements}

This research has been partially funded by the Spanish Ministry of Science and Innovation (projects TIN2008-03-23, TIN2011-28308-C03-02 and IPT-430000-2010-054) and the Autonomous Government of Castilla y León, Spain (projects VA293A11-2 and VA301B11-2). The authors would also like to thank the rest of GSIC/EMIC Group at the University of Valladolid for their support and ideas.

\section{References}

1. Jermann, P., Soller, A., Lesgold, A.: Computer Software Support for CSCL. In Strijbos, J.W., Kirschner, P., Martens, R., eds.: What we know about CSCL ... and implementing it in higher education. Volume 3 of Computer-Supported Collaborative Learning. Kluwer Academic Publishers, Norwell, MA, USA (2004) 141-166

2. Dillenbourg, P., Hong, F.: The mechanics of CSCL macro scripts. International Journal of Computer-Supported Collaborative Learning 3 (2008) 5-23 
3. Prieto-Santos, L.P., Holenko-Dlab, M., Gutiérrez, I., Abdulwahed, M., Balid, W.: Orchestrating technology enhanced learning: a literature review and a conceptual framework. International Journal of Technololgy Enhance Learning 3(6) (2011) 583-598

4. Martínez-Monés, A., Dimitriadis, Y., Harrer, A.: An interaction aware design process for the integration of interaction analysis in mainstream CSCL practices. In: Analyzing Collaborative Interactions in CSCL: Methods, Approaches and Issues. Springer Verlag (2011) 269-291

5. Lockyer, L., Dawson, S.: Learning designs and learning analytics. In: Proceedings of the 1st International Conference on Learning Analytics and Knowledge. LAK '11, New York, NY, USA, ACM (2011) 153-156

6. Villasclaras-Fernández, E., Hernández-Leo, D., Asensio-Pérez, J., Dimitriadis, Y.: Incorporating assessment in a pattern-based design process for CSCL scripts. Computer Human Behaviour 25 (September 2009) 1028-1039

7. Dillenbourg, P.: Over-Scripting CSCL: the risks of blending collaborative learning with instructional design. In: Three Worlds of CSCL. Can We Support CSCL? Open Universiteit Nederland, Heerlen (2002) 61-91

8. Kobbe, L.: Framework on multiple goal dimensions for computer-supported scripts (2005) Kaleidoscope Noe. Deliverable D29.2.1.

9. Conole, G., McAndrew, P., Dimitriadis, Y. In: The role of CSCL pedagogical patterns as mediating artefacts for repurposing Open Educational Resources, Hershey, USA (2011)

10. Hernández-Leo, D., Villasclaras-Fernández, E., Asensio-Pérez, J., Dimitriadis, Y., Retalis, S.: CSCL Scripting Patterns: Hierarchical Relationships and Applicability. In: Proceedings of the 6th IEEE International Conference on Advanced Learning Technologies, Kerkrade, The Netherlands, ICALT (2006) 388-392

11. Rodríguez-Triana, M., Martínez-Monés, A., Asensio-Pérez, J., Jorrín-Abellán, I., Dimitriadis, Y.: Monitoring pattern-based CSCL scripts: a case study. In Kloos, C., Gillet, D., Crespo García, R., Wild, F., Wolpers, M., eds.: Towards Ubiquitous Learning. Volume 6964 of LNCS. Springer Berlin, Heidelberg (2011) 313-326

12. Steen, M., Manschot, M., De Koning, N.: Benefits of Co-design in Service Design Projects. International Journal of Design 5(2) (2011) 53+

13. Visser, F.S., Stappers, P.J., van der Lugt, R., Sanders, E.B.N.: Contextmapping: experiences from practice. CoDesign: International Journal of CoCreation in Design and the Arts 1(2) (2005) 119-149

14. Voyiatzaki, E., Polyzos, P., Avouris, N.: Teacher tools in a networked learning classroom: monitor, view and interpret interaction data. In: Networked Learning Conference, Halkidiki, Greece (2008)

15. Rodríguez-Triana, M., Martínez-Monés, A., Asensio-Pérez: Monitoring Collaboration in Flexible and Personal Learning Environments. Interaction, Design and Architecture(s) Journal, special issue on: Evaluating Educative Experiences of Flexible and Personal Learning Environments. 11(12) (2011) 51-63

16. Alario-Hoyos, C., Wilson, S.: Comparison of the main Alternatives to the Integration of External Tools in different Platforms. In: Proceedings of the International Conference of Education, Research and Innovation. ICERI'10, Madrid, Spain (2010) 3466-3476

17. Hernández-Leo, D., Villasclaras-Fernández, E., Asensio-Pérez, J., Dimitriadis, Y.: Diagrams of learning flow patterns' solutions as visual representations of refinable IMS Learning Design templates. In: Handbook of Visual Languages for Instructional Design: Theories and Practices. IGI Global (2007)

18. Villasclaras-Fernández, E.D., Hernández-Leo, D., Asensio-Pérez, J.I., Dimitriadis, Y., Martínez-Monés, A.: Towards embedding assessment in cscl scripts through selection and 
assembly of learning and assessment patterns. In: Proceedings of the 9th international conference on Computer supported collaborative learning - Volume 1. CSCL'09, International Society of the Learning Sciences (2009) 507-511

19. Dillenbourg, P., Tchounikine, P.: Flexibility in macro-scripts for CSCL. Journal of Computer Assisted Learning 23(1) (2007) 1-13

20. Demetriadis, S., Karakostas, A.: Adaptive Collaboration Scripting: A Conceptual Framework and a Design Case Study. In: Proceedings of the 2nd International Conference on Complex, Intelligent and Software Intensive Systems. CISIS'08, Washington, DC, USA, IEEE Computer Society (2008) 487-492

21. Karakostas, A., Demetriadis, S.: Adaptation patterns in systems for scripted collaboration. In: Proceedings of the 8th International Conference on Computer Supported Collaborative Learning. Volume 1 of CSCL'09., Rhodes, Greece, International Society of the Learning Sciences (2009) 477-481

22. Fu, X., Hu, J., Teng, S., Chen, B., Lu, Y.: Research and Implementation on CSCW-Based Workflow Management System. In Shen, W., Yong, J., Yang, Y., Barthès, J.P.A., Luo, J., eds.: Computer Supported Cooperative Work in Design IV. Springer-Verlag, Berlin, Heidelberg (2008) 510-522 